\title{
Presença e ausência: o jogo do cuidado
}

\section{O lugar escuro: uma história de senilidade e loucura.}

SEIXAS, Heloisa.

Rio de Janeiro: Objetiva, 2007. 135 p.

"Foi no dia em que minha filha saiu de casa que minha mãe enlouqueceu" (p. 9). Assim começa a história de uma mãe contada por uma filha que tem uma filha com idade suficiente para sair de casa. Assim começa O lugar escuro: uma história de senilidade e loucura, da já conhecida escritora e também jornalista Heloisa Seixas. O livro é uma autobiografia da filha e uma biografia da mãe. Em sua ficha catalográfica temos a informação de que o livro é sobre a doença de Alzheimer. Não temos indicação de que se trate de uma autobiografia ou mesmo de uma biografia. O livro, que aparentemente fala de uma doença, começa com um duplo rompimento: o primeiro é o da filha de 22 anos, que junto com a mãe de 49 , espera o caminhão da mudança que virá por suas coisas. É uma filha de 22 anos que está saindo de casa por motivos e razões que desconhecemos e não nos será dito ao longo da narrativa; e o segundo rompimento, esse por sua vez o motor de toda a história, é o da mãe de 79 anos que não está saindo de casa, o rompimento da mãe é com outro lugar, o lugar da realidade, ela rompe com o real e passa a habitar a casa da loucura.

O lugar escuro vai contar o processo de loucura e definhamento físico e psicológico de uma mãe sob os olhos da filha. No decorrer da história ficamos conhecendo a vida de uma mulher forte, dura e fria que fez da força e da coragem suas principais características. E ficamos também, por meio da narrativa, conhecendo a relação dessa mulher tão forte com sua filha e a relação/reação dessa filha quando a mãe pouco a pouco vai se tornando um "bebê gigante". É por meio da experiência da filha que ficamos conhecendo a mãe e o que se sabe de suas experiências e memórias. Porém, essa filha ao narrar não é e nem quer ser imparcial, a mãe que nos é apresentada tem uma preferência declarada pelo filho homem. O olhar da filha para a mãe é um olhar de raiva e de mágoa, mas esse olhar não será todo o tempo mantido, e é justamente essa mudança que faz da experiência do cuidado um aprendizado.

A filha nos conta que a mãe casou em $1945 \mathrm{com}$ o homem que amava e que tinha dois anos e meio a menos que ela. Casou por procuração em Salvador, embarcando em seguida para Fortaleza, onde o marido a esperava, fato que quase matou a avó de desgosto. A mãe que sempre fora corajosa e decidida para a época preferiu adiar 0 nascimento dos filhos para aproveitar melhor 0 início do casamento freqüentando muitas festas, principalmente quando já morava no Rio de Janeiro. Sobre o casamento da mãe a filha diz que foi um casamento feliz. Contudo, quando os filhos ainda eram pequenos, a mãe foi abandonada pelo marido, em uma época em que mulher divorciada ainda era malvista, isso Ihe causou enorme dor por toda a vida e será sempre lembrado. "Ante a revelação de papai, minha mãe reagiu com altivez [...] Virou-se para ele e disse que "a porta da rua é a serventia da casa'. E ele foi embora" (p. 15).

Sobre o momento da separação da mãe ficamos sabendo que existe uma outra versão, a versão do pai, mas essa não é contada, é a mãe quem está em foco, e as queixas da filha na descrição dessa mãe são inúmeras. Ao falar da coragem física da mãe, a filha diz que esta era capaz de suportar imensas dores físicas e morais e sempre repetindo a expressão: "Minhas costas são largas" (p. 13). Isso fazia a filha se sentir fraca e diminuída diante da mãe, uma mulher jovial que nunca tivera preconceitos e estava sempre "à frente do seu tempo", criandoa com o irmão com bastante liberdade para a época. Uma mulher festeira, moderna e cosmo- 
polita que gostava de dançar e adorava carnaval. Cozinhava muito bem, possuía uma inteligência prática e uma habilidade manual que causava inveja na filha.

Com o avanço da narrativa de O lugar escuro, Seixas abre mão do tom de raiva na descrição de sua mãe e vai dando lugar a um sentimento de admiração e carinho. Ficamos sabendo de uma série de "dotes", qualidades dessa mãe, que vão se perdendo com o avanço da doença. A mãe jovial e sempre moderna cede espaço à rigidez e ao tradicionalismo das décadas de 1940 e 1950. A generosidade foi dando lugar ao egoísmo e à mesquinharia, a força e a coragem vão pouco a pouco abrindo caminho para a fragilidade e o medo, e a capacidade de administrar o próprio dinheiro desaparece. A mãe passou a ser sensível a qualquer dor, sua frieza foi substituída por uma necessidade gritante de carinho.

Com a constatação da doença da mãe, a filha teve de alterar seu cotidiano, foi necessário contratar enfermeiras para que a mãe fosse vigiada 24 horas por dia numa constante e frenética mudança de rotina. De um momento a outro a mãe tinha se tornado uma pessoa depressiva, maníaca e psicótica, e - Alzheimer era apenas mais um componente de uma acelerada demência senil.

Tentando entender a doença da mãe, a filha constata os inúmeros casos de loucura presentes na família, inclusa a sua própria, relatando no livro os momentos em que acredita ter estado perto da fronteira que foi transposta pela mãe e os mecanismos de controle adotados a partir do momento em que foi consciente da própria loucura. Esses mecanismos não puderam ser adotados pela mãe, que em sua loucura sofreu muito enquanto ainda estava consciente de que começava a perder o controle do real. A filha marca essa fase de transição com a frase da mãe: "Eu sei que estou enlouquecendo. Eu devia me matar" (p. 86).

Com a perda da realidade, a mãe, que era tão forte, deixa transparecer sua fragilidade física e emocional rememorando o abandono do marido, mas dessa vez mostrando as lágrimas tantas vezes escondidas. A mãe definha, míngua, e de repente temos a imagem daquela mulher de "costas largas" sempre tão firme e tão forte presa a uma cadeira de rodas, usando fralda, sendo alimentada como uma criança pequena e dormindo todas as noites em uma cama de hospital alugada que mais parecia um berço gigante.
"Foi no dia em que minha filha saiu de casa que minha mãe enlouqueceu" (p. 9). Até o momento dessa frase dentro da história, momento em que é considerado o "marco zero", quando a mãe transpõe a fronteira que separa a realidade da loucura, a filha ainda não tinha consciência do que acontecia com a mãe, é - momento de uma mudança sem retorno tanto para a vida da mãe quanto para a vida da filha, mas é a neta quem está mudando, é a neta quem sai de casa. São três gerações de mulheres que estão em um momento de mudança e de inversão de papéis. A neta sai de casa ganhando a sua independência e deixa vago o lugar de filha, que é ocupado imediatamente pela avó. A filha deixa de ser filha e passa a ser somente a mãe de sua filha, que sai de casa, e de sua mãe, que assume 0 lugar do cuidado desta. A mãe deixa de ser independente e autônoma e passa a estar dependente do cuidado e do carinho da filha.

O papel da mulher na família foi e ainda é um dos temas mais debatidos pelo feminismo. Durante um primeiro momento, nos séculos XIX e XX, bem marcado com a idéia de Virginia Woolf de um "quarto próprio", a família era considerada um local de aprisionamento, subordinante e opressivo da mulher. O lema feminista "o pessoal é político" vem justamente para incitar o rompimento com a idéia de espaços públicos para homens e privados para as mulheres, assumindo dessa forma uma luta pela libertação que significou, na prática, a possibilidade de a mulher romper com o padrão tradicional familiar a que estava submetida, negando juntamente $o$ postulado de maternidade obrigatória como realização máxima da mulher casada.

Esse pressuposto, como não podia deixar de ser, é bastante debatido pela corrente do feminismo social, que, após a década de 1970, acredita no valor da família e também da maternidade como fundamental para a consciência feminista; um princípio que vai de encontro à políitica de incentivo à realização das mulheres como cidadãs. ' O feminismo social tenta fazer da maternidade uma identidade feminina e necessária em termos políticos, retornando ao princípio patriarcal de que o lugar da mulher estaria no cuidado com a família em nome do que é chamado de "preservação da vida". Sob o nome de "política do desvelo", o feminismo social traz a idéia de que uma maior presença feminina nas esferas de poder abrandaria o caráter agressivo da atividade política, marcadamente masculina, abrindo 
espaço para o cuidado com os outros, a tolerância e a sensibilidade numa revalorização da esfera familiar que tem na figura da mãe a imagem da protetora e cuidadora; uma idéia de uma família que é muito mais idílica que real. Mary G. Dietz vai chamar esses pressupostos de inadequados para a consciência política feminista, pontuando que a linguagem do amor não desafia as instituições políticas e opressivas. ${ }^{2}$

Porém, no texto de Seixas não é o papel da mulher como cidadã que está sendo trazido para o campo da discussão; o que está sendo apresentado no texto é o papel da mulher na família. É a função do cuidado tradicionalmente imposta à mulher que desaba sobre ela sem que seja possível uma alternativa. A mãe é responsabilidade da filha, mas é também do irmão que sempre fora o preferido, mas essa responsabilidade não é mencionada.

Em O lugar escuro, o "cuidado" faz com que a filha se reconcilie com a mãe em uma aproximação violenta, porque é uma aproximação urgente e dolorosa, e necessária porque é somente dela a responsabilidade do cuidado com a mãe. A responsabilidade pelo cuidado segue sendo da mulher, mesmo que hoje já não se acredite numa impossibilidade do homem como cuidador, mesmo que hoje já esteja mais do que entendido que o "cuidar" é uma característica do humano e não do feminino exclusivamente. Pensando assim, poderia Seixas não cuidar de sua mãe esperando que seu irmão assumisse em seu lugar tal função?

Ao assumir a responsabilidade por sua mãe, Seixas faz da experiência do cuidado um aprendizado, ela reaprende a amar a mãe, sua raiva e seu ódio se desfazem com a compaixão gerada dia após dia de convivência com a doença. Ao mesmo tempo vem a constatação de que a mãe não está presente, está alheia, "sozinha em seu caminho de sombras" (p. 135), sozinha rumo ao final de sua viagem. A filha sabe que a mãe está lá, viva, mas o que sente é sua qusência.

Não é só do corpo da mãe que essa filha está cuidando, ao narrar sua experiência, Heloisa Seixas traz para a cena pública as memórias de sua mãe para que suas histórias não se percam. Ao mesmo tempo que ela marca a importância do cuidado com o outro, com o cuidado do que é velho, com o cuidado com aquele que se desconstruiu, seja pela loucura, seja pelo Alzheimer, seja pelo envelhecimento, ao narrar, Seixas consagra sua mãe para que seu "instante", sua vida, já não se perca. A cada vez que uma pessoa ler O lugar escuro, essa mãe ausente renascerá com toda sua força, com suas "costas largas".

\section{Notas \\ ${ }^{1}$ Mary G. DIETZ, 1999. \\ 2 DIETZ, 1999.}

\section{Referência bibliográfica}

DIETZ, Mary G. "Cidadania com cara feminista: o problema com o pensamento maternal". Debate Feminista, México, ano 10, volume especial (Cidadania e Feminismo), 1999.

Clarice Costa Pinheiro Universidade Federal de Santa Catarina 